\title{
Las experiencias organizativas por la repatriación de los restos de Rosas y los orígenes de la estrella federal como símbolo de identificación colectiva (1934-1954)
}

\author{
[The Organizational Experiences for the Repatriation of the Remains of \\ Rosas and the Origins of the Estrella Federal as a Symbol of Collective \\ Identification (1934-1954)]
}

Leandro Nicolás Pankonin

(PHiC-Universidad Nacional de General Sarmiento / CONICET)

leandro_pankonin@yahoo.com.ar

\section{Resumen:}

El presente trabajo analiza la formación de una tradición política rosista en la Argentina durante la primera mitad del siglo XX. Para tal fin, analizaremos las experiencias organizativas que reclamaron la repatriación de los restos de Juan Manuel de Rosas al Estado nacional durante dicho ciclo. Simultáneamente, prestaremos especial atención al hecho de haber sido en el marco de estas experiencias que la estrella federal, atendiendo a su morfología, irrumpió como una estrella roja de ocho puntas; al mismo tiempo que fue utilizada, por primera vez, como símbolo de identificación colectiva. Por último, pretendemos que este abordaje nos permita realizar una lectura paralela, o bien complementaria, a aquellas que han puesto en el centro de su análisis una dimensión estrictamente historiográfica del pasado rosista.

Palabras clave: Estrella federal; Rosismo; Repatriación; Usos del pasado

\begin{abstract}
:
The present work analyzes the formation of a rosista political tradition in Argentina during the first half of the XX century. To this end, we will analyze the organizational experiences that demanded the repatriation of the remains of Juan Manuel de Rosas to the national State during said cycle. Simultaneously, we will pay special attention to the fact that it was within the framework of these experiences that the estrella federal, taking into account its morphology, broke out as an eightpointed red star; at the same time that it was used, for the first time, as a symbol of collective identification. Finally, we intend that this approach allows us to carry out a parallel reading, or else complementary, to those that have put a strictly historiographic dimension of the rosista past at the center of their analysis.
\end{abstract}

Keywords: Estrella federal; Rosismo; Repatriation; Uses of the past

Recibido: 28/02/2020

Evaluación: 22/07/2020

Aceptado: 0112/2020

Anuario de la Escuela de Historia Virtual - Año 12 - N 19 - 2021: pp. 122-143.

ISSN: 1853-7049

http://revistas.unc.edu.ar/index.php/anuariohistoria 


\section{Las experiencias organizativas por la repatriación de los restos de Rosas y los orígenes de la estrella federal como símbolo de identificación colectiva (1934-1954) ${ }^{1}$}

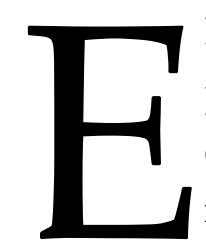

1 presente trabajo tiene por objetivo reconstruir la formación de una tradición política rosista a lo largo de la primera mitad del siglo $\mathrm{XX}$, prestándole especial atención a la producción de símbolos, espacios y rituales. Para esto nos focalizaremos concretamente en analizar las experiencias organizativas más salientes que tuvieron por objetivo la repatriación de los restos del otrora gobernador de la Confederación Argentina Juan Manuel de Rosas durante dicho ciclo. Concretamente las desarrolladas durante el año 1934, entre 1949 y 1951, y durante 1954. ${ }^{2}$ En este sentido no nos centraremos aquí, más allá de donde entendamos que el argumento lo amerite, en revisar las discusiones en torno a la figura de Rosas desarrolladas desde el ámbito estrictamente historiográfico. El recorte en cuestión responde al hecho de que fue en el marco de dichas experiencias organizativas donde localizamos, por un lado, una nueva morfología en aquello que era denominado como estrella federal, más precisamente una estrella roja de ocho puntas; y por otro, y de manera simultánea, sus primeros usos como símbolo de identificación colectiva. Prestaremos especial atención aquí al hito que significó su utilización como emblema de la Organización Popular por la Repatriación de los Restos de Rosas (de aquí en más OPRRR) del año 1954.

Llegado a este punto vale hacer una serie de aclaraciones. En primer lugar, debemos decir que este trabajo se inserta en una investigación mayor, que comenzó empujada por la convicción de que la estrella federal -en tanto estrella roja de ocho puntas- era un símbolo de larga data que había estado presente en la liturgia rosista del siglo XIX argentino. La motivación principal era perseguir los desplazamientos de este símbolo a fin de construir una genealogía que nos permitiera saber algo más sobre la cuestión nacional: trazar linajes, identificar tradiciones, apropiaciones, tensiones, etc. Pero allí donde fuimos a buscarla, no estaba. El camino fue mucho más sinuoso de lo que esperábamos. En segundo lugar, cabe subrayar que la correspondencia entre Rosas y el símbolo en cuestión, si bien no es "natural", tampoco ha sido aleatoria. Se ha construido sobre elementos materiales. Cabe decir, por ejemplo, que prácticamente las dos terceras partes de las publicaciones periódicas que el Instituto de Investigaciones Históricas Juan Manuel de Rosas (de aquí en más IIHJMR) -con lo central que dicha institución resultó

\footnotetext{
${ }^{1}$ Una versión preliminar de este trabajo fue presentada en las XVII Jornadas Interescuelas/ Departamento de Historia, octubre de 2019, San Fernando del Valle de Catamarca.

${ }^{2}$ Existen varios indicios de que existieron otras iniciativas pro-repatriación a lo largo de la primera mitad del siglo XX, pero con mucho menor impacto público y capacidad de articulación que las abordadas aquí. Esas indagaciones serán motivo de futuros trabajos.
} 
ser para el proceso de reposición pública de esta figura a lo largo del siglo XX-publicó entre 1939 y 2008 llevaron en su portada la estrella roja de ocho puntas. ${ }^{3}$ En el mismo sentido existen libros, tanto de historia como de ficción, sobre los años de la Federación en los que este motivo ocupó un lugar. ${ }^{4}$ Este símbolo también ha sido utilizado en muestras, ${ }^{5}$ museos, ${ }^{6}$ monumentos, ${ }^{7}$ escudos provinciales ${ }^{8}$ y en un billete. ${ }^{9}$ En tercer lugar, queremos llamar la atención sobre el problema de la distribución en el tiempo de los usos de la estrella federal, en tanto estrella roja de ocho puntas. Si bien este símbolo tuvo gran circulación a partir de la segunda mitad del siglo XX, y esos usos se ligaron a la figura de Rosas pero al mismo tiempo incorporaron nuevas capas de sentido, la situación para la primera mitad del siglo fue totalmente distinta. No hemos encontrado allí usos de la misma. Lo que sí hemos encontrado, y aquí cabe una cuarta aclaración, han sido apelaciones al uso de la planta euphorbia pulcherrima -o bien euphorbia poinsettia- , localmente conocida como estrella federal, como elemento vinculado a la figura de Rosas, o bien a su época. ${ }^{10}$

En términos teóricos, y volviendo sobre el problema de la confección de una tradición rosista durante la primera mitad del siglo $\mathrm{XX}$, nos apoyaremos en tres lecturas complementarias. Concretamente la mirada de Raymond Williams (2009, pp. 153-154) en torno al problema de la confección de las mismas y su énfasis en la creación de una

\footnotetext{
3 Todas las publicaciones del IIHJMR que llevaron una estrella federal en su portada se publicaron a partir de 1959.

${ }^{4}$ Existen una serie de autores que tanto desde la historia como desde la literatura han dado por sentada dicha presencia dentro de la liturgia de los años de la Federación. Ver: Félix Luna (1998, pp. 9-28); o bien las novelas históricas de María Rosa Lojo (1998 y 2005); o bien la investigación histórica de Michael Goebel (2013, p. 207), entre otras.

${ }^{5}$ En 2013 se desarrolló en la Biblioteca Nacional una muestra titulada "Aportes del Revisionismo a la Historia Nacional". El símbolo omnipresente de la muestra fue la estrella federal.

${ }^{6}$ El Museo Municipal Guardia del Monte, que expone el patrimonio histórico y cultural de la ciudad de San Miguel del Monte, tiene en exposición una baldosa que referencia a un uso "antiguo" de la estrella federal. También la entrada a la ciudad bonaerense de San Miguel del Monte está decorada con el símbolo de la estrella federal.

${ }^{7}$ El 20 de noviembre de 2010, en la celebración del “Día de la Soberanía”, se inauguró en el paraje de Vuelta de Obligado, un monumento que cuenta entre sus edificaciones principales, con una estrella federal.

${ }^{8}$ En 2005 Santiago del Estero incluyó en su escudo provincial el símbolo de la estrella federal.

${ }^{9}$ El billete de veinte pesos argentinos lleva en su portada el retrato de Rosas desde 1992. Desde el año 2000 se incorporó la planta de la estrella federal como transparencia.

10 Según nuestra propia investigación, de forma previa a 1954 los usos de la estrella federal se dieron básicamente bajo dos formas. O bien como alusión a la planta localmente conocida con ese nombre; o bien simplemente como sintagma. En ambos casos, más de una vez, se la utilizó como motivo vinculado a la época de Rosas, pero ninguno de aquellos estuvo vinculado a una estrella roja de ocho puntas. En ese sentido vale subrayar que, salvo una excepción (el periódico La estrella federal del norte que sacó tres números en Tucumán durante 1841 e hizo uso del sintagma, pero no así de la imagen), no hemos identificado ningún tipo de uso de la estrella federal en el siglo XIX. La primera intersección entre la planta y la época de Rosas data de una novela de Julio Cobos Daract de 1921, titulada justamente Estrella federal, donde esta hace las veces de símbolo de amor en una pareja que se enamora en la Buenos Aires de 1838-1839. Luego de lo cual volvió a circular con cierta cadencia en un cúmulo de letras de la música popular y radioteatros, con énfasis en las composiciones de Héctor Pedro Blomberg y Enrique Maciel, vinculadas al ciclo federal de Ignacio Corsini. Estas cuestiones, junto con otras, han sido desarrolladas con profundidad en mi tesis de maestría Los avatares del rosismo y la historia de los usos de la estrella federal (1921-1954).
} 
visión selectiva del pasado a fin de fortalecer un proceso de identificación determinado. En segundo lugar, la acepción thompsoniana de este concepto, con acento en el movimiento pasado-presente, orbitando centralmente en el problema de la experiencia y en los materiales con que las mismas se van entretejiendo y actualizando (Thompson, 2012, p. 47). Por último, los aportes de Eric Hobsbawm, (2002, pp. 7-8) atendiendo al problema de la propia inventiva de las mismas, a través de la creación y recreación de una narrativa hecha de símbolos, espacios y rituales. Pretendemos ver el modo en el que el rosismo utilizó el pasado en determinadas coyunturas, al mismo tiempo que encontrar los instrumentos para analizar la historicidad de dicha tradición, así como los espacios, celebraciones e iconografías a los que apeló. Concretamente el modo en que se fue vertebrando a sí misma y cuáles fueron los vaivenes de su acumulación histórica, sus posiciones relativas en cada coyuntura y, por lo tanto, su posición cambiante en cada campo de fuerzas a lo largo de la primera mitad del siglo XX. Así, buscaremos analizar los contextos en que se desenvolvieron dichas iniciativas, quiénes integraban las comisiones, cuáles fueron los sentidos sobre los que se construyeron dichos reclamos y cómo se desarrolló el proceso a través del cual el rosismo pasó, dentro de los imaginarios nacionales, de una posición subalternizada a una emergente -especialmente a partir de los años treinta-.

Indagar este derrotero tiene para nosotros una importancia fundamental por tres motivos. Porque a través de estas formas organizativas se articularon un conjunto heterogéneo de expresiones rosistas, logrando aglutinar esa identidad en cada coyuntura; porque trabajar sobre el registro del rosismo nos permitió concentrarnos en una categoría capaz de contener dentro de sí a un cúmulo de expresiones reivindicativas de la figura de Rosas, que incluyeron a las vertientes historiográficas revisionistas, pero al mismo tiempo las excedieron; y, finalmente, porque es en 1954 que la OPRRR adoptó como emblema propio una estrella roja de ocho puntas, denominada estrella federal, generando un punto de inflexión fundamental en la historia de este símbolo.

\section{Rosas y sus representaciones}

Existe una idea compartida de que la década del treinta significó un punto de ruptura respecto a la irrupción de representaciones de Rosas y su época en la agenda pública de nuestro país. En ese sentido la dimensión estrictamente historiográfica ha tenido una centralidad particular en la forma de abordar este problema. En Los males de la memoria (1995), Diana Quattrocchi Woisson expuso las formas en que cierta memoria -en los términos de la autora- devino en historia oficial: la historiografía liberal fundada por Bartolomé Mitre. Su investigación buscó mostrar la imposibilidad de estabilización del campo historiográfico argentino, permanentemente amenazado por una contra memoria con voluntad de construirse en contra historia y, más aún, en historia oficial. En su argumento, fue "el objeto Rosas" el "verdadero instrumento de contrahistoria" (1995, p. 81). El trabajo de Quattrocchi Woisson, precursor en el desarrollo de las discusiones 
sobre las formas en que la sociedad argentina en distintas coyunturas usó y accedió al pasado, incurrió en el problema de reproducir y fortalecer la idea de que el campo historiográfico argentino -al menos de la primera mitad del siglo $\mathrm{XX}$ - era un territorio partido en dos mitades enfrentadas de manera irreconciliable. Es decir, identificó el choque frontal y manifiesto entre dos polos, pero no el poder disperso, la interacción y la circulación de representaciones que puede haber habido en otros ámbitos, e incluso las formas de circulación dentro de estos dos polos. Subrayamos que a la hora de explicar las razones históricas de la "reactualización" del rosismo en dicha coyuntura, la autora puso en consideración una serie de elementos entre los que recalcó el fenómeno yrigoyenista (1995, p. 49). Más cerca en el tiempo, Michael Goebel publicó La Argentina partida: Nacionalismos y políticas de la historia, cuyo enfoque no se desarrolló en torno al problema de la memoria, sino que fue construido a partir del concepto de "política de la historia", entendido como "las formas en que se escribe y moviliza la historia con el objeto de afectar la distribución del poder político en una sociedad" (Goebel, 2013, p. 11). Este trabajo continúa al anterior en la propuesta de exponer un campo fracturado. En sus propios términos, en la Argentina se naturalizó la construcción de un "biculturalismo", una matriz interpretativa acerca de la identidad nacional entendida como una separación entre dos tradiciones político-culturales: la "liberal" frente a la "nacionalista" (Goebel, 2013, p. 287). Así las cosas, Rosas representó una evocación central para esta última. Resulta paradójico que ambos trabajos, que procuraron elaborar una crítica al revisionismo, quedaron en definitiva seducidos por sus proposiciones y terminaron por asumir la operación historiográfica del revisionismo que consistió en afirmar que la Argentina había tenido una historia "oficial" a la que el revisionismo llegó a poner en jaque.

Fernando Devoto y Nora Pagano, en el capítulo de Historia de la historiografía argentina dedicado al revisionismo histórico, repararon en el hecho de que:

Éste [el revisionismo], en cualquier definición que elijamos, sólo puede ser entendido en una dinámica temporal, a la vez como una secuencia de etapas y como una tradición acumulativa de rasgos, problemas y elementos identificatorios. A la manera de un río correntoso, las sucesivas épocas revisionistas se dilatan, se contraen, se reformulan, se combinan con diferentes contextos políticos y culturales y a la vez sedimentan en un conjunto de motivos y de lugares de memoria que sirven a los partícipes para identificarse. En esa flexibilidad puede quizás encontrarse una de las razones de su perdurabilidad (Devoto y Pagano, 2009, pp. 202-203).

En consonancia con dicha definición, procuraron observar la pluralidad de autores que han sido contemplados dentro de esta definición y, en ese sentido, la pluralidad de interpretaciones a las que -dependiendo de quién lo enuncie, cuándo y por qué- puede asignarse el mote de revisionista. Es importante resaltar que Pagano y Devoto ponderaron el proceso expansivo de públicos lectores durante la década de 1920 y 
ubicaron allí, en el consumo por parte de estos sectores de "cuestiones y controversias históricas en un formato ciertamente no académico sino entre la divulgación y el folletín", un emergente donde la figura "controversial" de Rosas ganó interés (2009, p. 209). Por su parte, María Laura Reali, mostró una serie de vaivenes en la apelación revisionista, que permiten relativizar ciertas ideas en torno a la dimensión espacial y temporal de este problema en la historiografía regional, dando cuenta de una serie de interconexiones que permiten pensar este fenómeno en una escala transnacional, aunque siempre motorizado por vectores propios de cada tradición nacional. La propuesta de esta autora permite pensar a la historiografía revisionista con una historicidad previa a la década de 1930, que puede haber asumido nuevas formas en dicha coyuntura. Una de ellas, central para nuestro análisis, resultó ser el lugar que pasó a ocupar Rosas en dicha corriente historiográfica, de allí en más, para el territorio rioplatense. Su planteo da cuenta de lo importante que esa figura pasó a ser en los años treinta, al mismo tiempo que deja ver que Rosas y el revisionismo no son necesariamente elementos intercambiables entre sí. ${ }^{11}$

Siguiendo con las observaciones a propósito de la coyuntura en que la figura de Rosas irrumpió en la agenda pública, Tulio Halperín Donghi señaló el modo en que se imbricaron la "crisis" atravesada por la Argentina de fines de la década del veinte, consistente en haber "descubierto" su desplazamiento del destino de grandeza imaginado hasta entonces, y la creciente "tormenta del mundo" desenvuelta en esos años, haciendo alusión al curso tomado por el país a partir de 1930, afirmó que:

quienes emprendían el examen eran los marginados por el orden político que dominaba el presente argentino, y estaban de antemano dispuestos a buscar en su exploración del pasado nacional los materiales para una implacable acta de acusación contra las corrientes y tradiciones políticas de las que ese orden se proclamaba orgullosamente heredero (Halperín Donghi, 2003, p. 52).

Por su parte, Darío Macor prestó atención a la invención de la década del treinta en el debate político intelectual de la Argentina sesentista y buscó horadar la naturalización de la "década del treinta" como unidad de sentido, para dejar expuesto que "su invención" resultó ser:

producto del debate político/ideológico que, provocado inicialmente por el quiebre del "consenso liberal" acelerado precisamente por la gran crisis con

\footnotetext{
${ }^{11}$ Reali, 2016; Echeverría y Reali, 2016. Resulta paradigmático el lugar que el pasado rosista pasó a ocupar en el discurso y la práctica política del uruguayo Luis Alberto de Herrera, cuando el problema del imperialismo se fue haciendo cada vez más acuciante para su país, y la región. Lo cual significó una posición distinta con sus producciones revisionistas previas, donde la figura de Rosas había sido objeto de críticas (Reali, 2015, pp. 222-223).
} 
la que se inicia la década, alcanzará su mayor densidad a partir de la caída de Perón y hasta bien entrada la década del setenta (Macor, 1995, p. 2).

En diálogo con la operación que Macor desenvolvió allí, creemos que es dable matizar, por un lado, el lugar que algunas imágenes de la "década del treinta" le otorgaron a Rosas, y por otro lado, considerar que dicha "invención" pudo haber aplastado otras imágenes de Rosas que se encontraban en circulación en esos años, habiendo jerarquizado al revisionismo en una lectura hecha al calor de los años sesenta.

En la saga de esfuerzos que durante las últimas décadas se han hecho con ánimo de construir una mirada de mayor complejidad sobre las formas de usar el pasado, y prestando especial atención a lo sucedido durante la primera mitad del siglo XX, Alejandro Cattaruzza remarcó que:

durante el período de entreguerras podía verse la lenta consolidación de otro centro posible para la tradición argentina. Hasta los centenarios, Mayo aparecía en soledad; [...] funcionaba simbólicamente como episodio fundacional de la tradición política nacional, aquella que era específicamente argentina. Aquel otro centro posible de la argentinidad se rastreaba en producciones culturales rurales previas, más antiguas y primordiales, asociadas sin más precisión a un tipo social y ubicadas temporalmente en la colonia. Tanto una como otra argumentación poseían flancos visibles y eran, en un sentido, invenciones [...]. En principio, [...] todas ellas remiten al pasado; [y] su eficacia en la creación de sentido común no depende de su respaldo empírico o de su rigor científico, sino, una vez más, de condiciones político-culturales presentes, que impactan en su circulación y recepción (Cattaruzza, 2017, p. 73).

Es, compartimos, bajo ese encuadre que debe ser interpretada la irrupción de Rosas en la agenda pública de esos años, y bajo el prisma de lo que -este mismo autordenominó como "usos del pasado". Estos comprenden una variedad de imágenes, representaciones y evocaciones que pueden ser concebidas como puntos de condensación de un proceso de interpretación del pasado con el fin de intervenir en ellas tornando legítimas las posiciones presentes e influyendo en las coyunturas en las cuales se desenvuelven (Cattaruzza, 2007, pp. 18-19).

Será a la luz de estos elementos, que analizaremos las experiencias organizativas que reclamaron al Estado argentino por la repatriación de los restos de Rosas a partir de la década del treinta. Reconocemos como antecedente de este trabajo el realizado por Ana María Barletta y Gonzalo de Amézola (1992). Más aún, todos los trabajos que acabamos de revisar aludieron, de un modo u otro, a alguna de dichas comisiones, pero en todos los casos la operación consistió en analizarlas -en menor o mayor medida- como epifenómeno de los debates historiográficos. Para ser más concretos, nos interesa analizar la dinámica interna de esas experiencias, no ya a la luz de los debates historiográficos sino -y si es que cabe la diferencia- en un plano que atienda más a la 
dimensión político-organizativa, lo cual -entendemos- nos permitirá incorporar y contemplar importantes elementos de análisis para caracterizar al devenir rosista. Sobre todo si tenemos en cuenta que fue en este ámbito, y no en otro, donde se dieron los primeros usos de la estrella federal como símbolo de identificación colectiva.

\section{Los orígenes del rosismo organizado}

En junio de 1934, el reclamo por la repatriación de los restos de Rosas comenzó a tomar forma organizativa. La misma se gestó en la ciudad de Santa Fe. Alfredo Bello asumió el rol de presidente de la naciente comisión y Clementino Paredes la vicepresidencia. ${ }^{12}$ Dicha entidad asumió como tarea "que se constituyan comisiones similares en la metrópoli y en las demás provincias". ${ }^{13}$ Con el correr de los días comenzaron a recibir adhesiones de distintos puntos del país y a coordinar acciones con otros núcleos rosistas. ${ }^{14}$ La respuesta no se hizo esperar, y el diario La Nación publicó una editorial referida a este tema el 21 de junio. Allí se afirmaba que la "sola enunciación de ese propósito pone naturalmente en movimiento un cumulo de ideas y sentimientos arraigados desde hace casi un siglo en el alma argentina", ante lo cual "no podemos permanecer indiferentes", dado que, en sus propios términos, esa iniciativa significaba la "prescripción de un fallo histórico que no cabe sea alterado en su significación fundamental".$^{15}$

La iniciativa santafesina por repatriar a Rosas no tardó en confluir con otra asentada en la ciudad de Buenos Aires. Tras realizar una convocatoria desde las páginas de $\mathrm{La}$ Razón, ${ }^{16}$ una asamblea reunida en el salón de actos de dicho diario, resolvió "por aclamación" confirmar para la presidencia de la Junta por la repatriación de los restos de Rosas a Dardo Corvalán Mendilaharzu, un hombre afiliado a la Unión Cívica Radical (UCR), que había actuado como Secretario de Culto del Ministro de Relaciones Exteriores y Culto de la Nación bajo la gestión de Horacio Oyhanarte durante la segunda presidencia de Hipólito Yrigoyen. Llevaba escrito para entonces varios libros entre los que valen destacar dos contribuciones tempranas a la reivindicación rosista durante la década del diez y otras dos del mismo tono, que cobraron mayor visibilidad durante la década siguiente. Su incentivo a la empresa repatriadora tampoco era novedosa. Ya se había manifestado al respecto, junto a otras figuras, a fines de los años veinte. ${ }^{17}$ Formó

\footnotetext{
${ }^{12}$ El Liberal, 18 de junio de 1934, en: Colección Recortes Emilio Ravignani/Instituto de Historia Argentina y Americana “Dr. Emilio Ravignani” [de aquí en más: CRER/IHAAER] -Varios. Tomo II, p. 290.

${ }^{13}$ La Nación, 20 de junio de 1934, en: CRER/IHAAER/LN-LP. T. XIX, p. 338.

${ }^{14}$ La Prensa, 17 de junio de 1934, en: CRER/IHAAER/LN-LP. T. XIX, p. 314.

${ }^{15}$ La Nación, 21 de junio de 1934, p. 6.

${ }^{16}$ La Razón, 26 de junio de 1934, p. 7.

17 Tanto Corvalán de Mendilaharzu, como otras figuras, se habían manifestado al respecto en una encuesta realizada por el diario Crítica entre diciembre de 1927 y enero de 1928. Así lo manifestó también, para la misma época, en comunicación con el uruguayo Germán Roosen, asumiéndolo ya como una cruzada rioplatense que podría ser materializada en caso de que Yrigoyen volviera a gobernar la Argentina y Luis Alberto de Herrera hiciera lo propio en el Uruguay (Reali, 2015, p.189).
} 
parte del IIHJMR y más tarde de la Academia Nacional de Historia (ANH). Este último y Alfredo Bello, en representación de la filial santafesina, agradecieron a la dirección del diario por alojarlos, al mismo tiempo que recordaron al fallecido José A. Cortejarena director y propietario del diario La Prensa entre 1911 y 1921- por haber participado en una fugaz iniciativa del mismo tipo en 1917. El mismo Corvalán subrayó la voluntad de preparar un homenaje "sin rencores". Ese día la asamblea resolvió colocar el 9 de julio una ofrenda floral en la estatua del General San Martin, situada en la plaza de mismo nombre de la ciudad de Buenos Aires, y realizar una lectura de cartas de este a Rosas. ${ }^{18}$ Llegado ese día, el cronista del diario La Razón subrayó la "crecida cantidad de público". El único en tomar la palabra fue el presidente de la Junta, luego de lo cual se colocó una corona de laureles con un lazo azul y blanco y se gritaron vivas a la patria. ${ }^{19}$ Este acto dejó instalada la discusión. Unos días después, el diario La Prensa volvió a encargarse del tema, esta vez con suma preocupación al afirmar que:

Según ha podido verse en las informaciones correspondientes actívanse en estos días algunos intentos de reivindicación para la memoria de Juan Manuel de Rosas. No se trata ya de páginas de historiador que aspira a modificar ligeramente el juicio rotundo que la posteridad de Rosas formó sobre su vida y su obra, sino de actos públicos encaminados a producir una adhesión popular que no es conveniente cuando todavía el criterio de la historia no ha evolucionado en su última palabra sobre el tirano. ${ }^{20}$

Si bien, entrado el mes de agosto, la visibilidad de las comisiones en la prensa se hizo más opaca, las distintas filiales siguieron en actividad, y a principios de septiembre anunciaron la definitiva constitución de la comisión nacional con su nómina de miembros. ${ }^{21}$ Dos meses más tarde, con motivo del aniversario del combate de Vuelta de Obligado, la organización dio circulación a su único documento público titulado ; $A l$ Pueblo Argentino! bajo el sello de la Junta Americana de Homenaje y Repatriación de los Restos del Brigadier General Don Juan Manuel de Rosas (de aquí en más JAHRRR). Allí sentaron posición sobre su razón de ser y sus objetivos:

Debíamos estos conceptos a la opinión pública desde el momento en que constituimos la organización a cuyo cargo está no solo la realización del propósito patriótico de reintegrar los restos beneméritos del General Rosas al seno siempre acogedor de la tierra nativa, sino de contribuir a depurar la

\footnotetext{
${ }^{18}$ La Razón, 3 de julio de 1934, p. 4.

${ }^{19}$ La Razón, 9 de julio de 1934, p. 10.

${ }^{20}$ La Razón, 14 de julio, en: CRER/IHAAER/VARIOS. T. II, p. 268.

${ }^{21}$ La Razón, 3 de septiembre de 1934, en: CRER/IHAAER/VARIOS, T. III. José María Rosa remarcó ciertos cambios con respecto a la mirada depositada sobre el proceso organizativo pro-repatriación, ya que "todos los periódicos "serios" -que hasta ese momento habían dado hospitalidad a los comunicados de las "comisiones de repatriación" que se formaban en la Republica- hacen silencio para sus actividades". En: José María Rosa (1979, p. 139).
} 
131 Las experiencias organizativas por la repatriación de los restos de Rosas

historia de las informaciones con que se ha deformado y negado su personalidad y su rol histórico. ${ }^{22}$

Así las cosas, allí se enunciaron tres elementos centrales que bien valen para pensar la intervención rosista en dicha coyuntura. La primera es la apelación a Rosas como garante, de cara al pueblo, de lo conseguido en Mayo de 1810, y no como su contractara -como ha sido catalogado más de una vez-. Concretamente en la afirmación de que "no se impuso como un faccioso usurpando del poder, sino que por el contrario "fue el pueblo" quien lo puso allí "para asegurar el patrimonio de Mayo", frente a los "propósitos de conquista" extranjeros. A lo que agregaron, de inmediato, que fue "el mismo pueblo" con "lo más representativo de la Nación" quien los sostuvo hasta el final de su Gobierno. ${ }^{23}$ Este enunciado se encolumnó con un segundo elemento, a saber una fuerte reivindicación sobre la campaña militar conducida por Rosas contra las comunidades indígenas de la pampa y nor-patagonia entre 1833 y principios de 1834 . En pocas palabras afirmaron que "haber mantenido a raya al salvaje" significó "su verdadera y grandiosa contribución a la causa de la independencia". ${ }^{24}$ Más aún, de esta manera se encargaron de ponderar a la figura de Julio A. Roca como heredero de la gesta iniciada por Rosas. Por último, y tal como la acción de presentación pública de esta organización lo hizo patente, una alta cuota de la operación le cupo aquí a seguir abonando al tándem Rosas-San Martín. Así las cosas, concluyeron en exponer el problema de que Rosas no solo es "el único de los grandes que aún sufre la proscripción", sino que además "se maltrata" su memoria. ${ }^{25}$ Llegado a este punto, es dable afirmar que el imaginario construido en torno a Rosas por la comisión de 1934 apeló fuertemente a edificar una línea histórica entre Mayo, San Martín, Rosas y Roca.

No hemos podido reconstruir el devenir de esta experiencia más allá del comunicado de noviembre de 1934. Pero queremos subrayar lo señero de la experiencia organizativa que venimos reconstruyendo aquí en la formación de dos instituciones centrales para la consolidación de una tradición rosista durante las siguientes décadas. Más aún, creemos que es dable afirmar que tanto la formación del Instituto de Estudios Federalistas (IEF) - con centro en la ciudad de Santa Fe- en junio de 1938, como la inmediatamente posterior creación del IIHJMR -con centro en la ciudad de Buenos Aires- en agosto del mismo año, pueden ser entendidos -al menos en parte- como un saldo organizativo de aquella experiencia (Coudannes Aguirre, 2009, p. 23). Ambas desarrollaron publicaciones propias. Cabe subrayar que ninguna publicación del IIHJMR utilizó en su portada una estrella federal hasta julio de 1959, cuando -luego de su reapertura, tras haber sido clausurado en 1955- comenzó a salir un boletín titulado La Estrella Federal, símbolo de revisión en la historia. Por la cultura popular histórica.

\footnotetext{
22 JAHRRR, jAl Pueblo Argentino!, Buenos Aires, 1934, p. 3.

${ }^{23}$ JAHRRR, jAl Pueblo Argentino!, Buenos Aires, 1934, p. 5.

${ }^{24}$ JAHRRR, ;Al Pueblo Argentino!, Buenos Aires, 1934, pp. 8-9.

${ }^{25}$ JAHRRR, ;Al Pueblo Argentino!, Buenos Aires, 1934, p. 25.
} 


\section{El rosismo, el pueblo y la unidad nacional}

El Instituto Nacional Sanmartiniano, creado originalmente en 1933 y oficializado como dependencia del Estado nacional a partir de 1944, asumió el rol rector de definir los alcances "lícitos" de la doctrina sanmartiniana. Bajo ese designio emitió el 29 de noviembre de 1948 una declaración relativa "a la naturaleza de las relaciones entre el Libertador y el Gobernador de Buenos Aires, Don Juan Manuel de Rosas" ${ }^{26}$ La respuesta no tardó en hacerse esperar. El IIHJMR, por un lado, y Alejandro Olmos, por otro, abrieron la polémica. Con ánimo de focalizarnos en la organización pro-repatriación de los restos de Rosas impulsada por este último tiempo después, nos abocaremos a sus intervenciones. Olmos había nacido en Tucumán el $1^{\circ}$ de mayo de 1924. Estudió derecho y desde su juventud comenzó a vincularse a su coterráneo José Luis Torres, creador del célebre mote de "década infame". Junto a él forjó una posición nacionalista y antiimperialista. Olmos vio con buenos ojos el nacimiento del peronismo, pero rápidamente se manifestó en contra de la firma argentina de las Actas de Chapultepec en 1946. Su relación con Perón fue sumamente tirante y estuvo llena de vaivenes hasta 1955, cuando -luego del golpe- asumió la dirección del periódico Palabra Argentina, que no tardaría en convertirse en una de las expresiones centrales de la resistencia peronista (Galasso, 2006, pp. 19-32). En cuanto a su reivindicación sobre la necesidad de integrar el legado rosista y sanmartiniano, procuró abrir un debate público al respecto con Bartolomé Descalzo - presidente del INS-, el director del diario La Nación e incluso el presidente de la nación, Juan D. Perón. ${ }^{27}$ El 12 de agosto de 1949, como corolario de estas intervenciones, quedó constituida la Comisión Popular Argentina Para la Repatriación de los Restos del Brigadier General Don Juan Manuel de Rosas (de aquí en adelante CPAPRJMR). En su carta orgánica quedaron plasmados sus objetivos centrales: repatriar los despojos mortales de Rosas, promover un "movimiento de opinión pública a favor de la justa reivindicación del Restaurador" haciendo caso a los designios hechos en vida por San Martín, realizar una "vasta campaña de divulgación" para poner al alcance del pueblo "la realidad del pasado de la Patria", abocarse al "estudio integral de la historia argentina" y "bregar por el triunfo de la verdad y de la justicia histórica, por la recuperación del espíritu nacional y por la unidad de todos los argentinos". ${ }^{28}$ Aquella carta expresaba la voluntad de construir una gran organización de base territorial con alcance nacional. La misma llevaba las firmas de la Junta Nacional conformada por David Uriburu, el Almirante (R) León Scasso, Alejandro Olmos, Pedro E. Millán, Horacio R. de León Belloc, Julio Molina, Ramón Doll y el Coronel (R) Arturo A. Saavedra. El primero era sobrino de José Félix Uriburu y había oficiado como jefe de la policía durante el interregno que duró su gobierno. Años más tarde adhirió al golpe militar del GOU en 1943, se desempeñó como interventor de la provincia de Corrientes durante 1944 y fue

\footnotetext{
${ }^{26}$ El documento en cuestión es: Bartolomé Descalzo (1949).

${ }^{27}$ El conjunto de estas misivas, se publicaron en un solo volumen: Olmos (1949).

${ }^{28}$ Juan Manuel, 1 de noviembre de 1951, p. 6.
} 
candidato a diputado por la Alianza Libertadora Nacionalista (ALN) en 1946 (Fernández Lalanne, 1989, p. 462). Saavedra, por su parte, era para entonces un oficial retirado del ejército que había formado parte del grupo fundador del GOU. Luego del golpe de junio de 1943, asumió la jefatura del Regimiento 1 de Infantería y, en 1944, fue designado como gobernador militar de la Provincia de Santa Fe. Horacio R. de León Belloc cumplía para entonces funciones diplomáticas en la embajada argentina en Canadá. Con respecto a Scasso y Ramón Doll vale decir que habían formado parte de la ALN (Besoky, 2016, p. 52). Tal como lo planteamos para el caso de Olmos, podemos afirmar que la totalidad de este núcleo estaba conformado por figuras fuertemente identificadas con las ideas nacionalistas y con cierta tirantez con el liderazgo de Perón.

El 6 de mayo de 1950, al cumplirse cien años de la fecha de envío de la última carta escrita por José de San Martín a Juan Manuel de Rosas, y mientas se desarrollaban en todo el país las actividades oficiales concernientes al "Año del General San Martín", la CPAPRJMR emitió un comunicado Al Pueblo Argentino. Dando continuidad a los debates expuestos anteriormente, buscaron explicitar los vínculos de Rosas con el homenajeado aquel año, de manera tal que reconocer a San Martín en la centralidad simbólica de la nación significara también reconocer al primero en el mismo lugar. El comunicado afirmaba que la tarea de dicha comisión no se reducía a recuperar los restos de Rosas, sino que:

tal realización será el corolario obligado de una obra de significación mayor: la rectificación de los conceptos; la formación y estímulo de un sentido misional de hispanidad, nacionalidad y Patria; y la identificación popular con el imperativo sanmartiniano, a concretarse en la unidad espiritual de los argentinos.

Se insistía allí en dejar de lado "distinciones políticas", para desarrollar un movimiento de carácter "exclusivamente nacional", un "movimiento espiritual" para "lograr la formación de una conciencia argentina en la unidad integral de la Nación" ${ }^{29}$ El mismo 6 de mayo, la Comisión volvió a interpelar al INS. Mediante el obsequio de un retrato de Rosas, invitaron a dicha institución a incorporarlo en su galería de la "Casa de San Martín", a lo que el presidente del Instituto contestó con una negativa. Días después el diario La Prensa se hizo eco de este intercambio abonando argumentos contra Rosas. ${ }^{30}$ La CPAPRJMR reunió todos esos documentos, junto con las fuentes históricas que justificaban su propia posición, en un segundo folleto. Allí afirmaron: "La Comisión Popular Argentina se halla en pie en toda la República y bregará porque el pueblo argentino rinda a don JUAN MANUEL DE ROSAS el 'justo reconocimiento' ordenado por San Martín". ${ }^{31}$

\footnotetext{
${ }^{29}$ CPAPRJMR, Al Pueblo Argentino, mayo de 1950, p. 2.

${ }^{30}$ La Prensa, 21 de mayo de 1950.

${ }^{31}$ CPAPRJMR, Niegan a San Martín, mayo de 1950, p. 5.
} 
A lo largo de ese año, la CPAPRJMR realizó una serie de actos como parte de su campaña. El 12 de junio, en la ciudad de Corrientes, gran cantidad de público llenó las instalaciones del Salón Monumental, que se encontraba "engalanado con los colores nacionales y adornado con estrellas federales". Esto nos da la pauta de la incorporación, ya para esta época, de la planta a la ornamentación rosista. Vale decir que, de momento, no hemos encontrado usos similares anteriores. La escena se completaba con un gran retrato de San Martín y otro de Rosas. El primer orador aquel día fue Raúl Puigbó, representante de la CPAPRJMR en la provincia. Este junto a su hermano Juan Gabriel, habían impulsado el armado de la ALN en Corrientes años atrás. En 1949, tras romper con la misma, Raúl formó parte de la creación del Movimiento Sindical Nacionalista y años después se integró a los comandos civiles que acecharon al gobierno de Perón durante 1955. Tuvo un breve paso por el gobierno de Lonardi hasta ser desplazado con el advenimiento de Eugenio Aramburu a fines de ese mismo año (Besoky, 2016, p. 295). El acto continuó con las palabras de David Uriburu y concluyó con un discurso de la señora Giró de Llano, quien intervino en representación de las mujeres correntinas. ${ }^{32} \mathrm{~A}$ finales de ese mismo mes, el 30 de junio, la Comisión realizó un nuevo acto en el salón "La Argentina" de la ciudad de Buenos Aires que "colmó la capacidad de la sala". Ese día los dos únicos oradores fueron José María Rosa y Alejandro Olmos. Este último afirmó en su discurso que el movimiento por la repatriación de Rosas tenía "un contenido espiritual que trasciende a la finalidad misma de la Nación". A lo que agregó:

Queremos recuperar integralmente a Rosas [...]. Queremos recuperar no la violencia, ni implantar el concepto despótico de Estado. Queremos nutrir a la Nación de ese sentimiento telúrico de amor a la tierra que tuvo en Rosas su expresión más perfecta.

Para finalizar diciendo que Rosas "vendrá no repudiado como tirano, sino exaltado en la cumbre misma de su gloria de gaucho y de patriota, en el brillante mediodía de la justicia histórica". ${ }^{33}$ La presencia de Rosa allí es un elemento importante para destacar. Si bien, todo indica que no formó estrictamente parte de esta organización, este es un claro indicio de que sí dio su apoyo a la iniciativa justo en los momentos previos a constituirse él mismo como presidente del IIHJMR. Más aún, vale tener en cuenta que la CPAPRJMR y el IIHJMR tuvieron una serie de declaraciones cruzadas sobre la pertinencia o no del movimiento pro-repatriación desarrollado entre 1949 y 1951. Fue justamente durante esos años que buena parte de la composición inicial del IIHJMR se estaba horadando y pujaba cada vez con más fuerza un sector preocupado, entre otras cosas, por hacer que el rosismo tuviera un impacto masivo mayor al que había

\footnotetext{
${ }^{32}$ Juan Manuel, 9 de agosto de 1951, p. 4.

${ }^{33}$ Juan Manuel, 26 de julio de 1951, p. 8.
}

Anuario de la Escuela de Historia Virtual - Año 12 - N 19 - 2021: pp. 122-143. ISSN: 1853-7049 
desarrollado hasta entonces. ${ }^{34}$ No es difícil pensar que la experiencia desarrollada durante 1954 decantó en buena medida de los alcances y limitaciones de lo construido entre 1949 y 1951, al mismo tiempo que pareciera haber tenido la capacidad de contenerla dentro de sí.

La CPAPRJMR se consolidó, en buena medida, a lo largo de 1951. Adoptó como emblema de identificación a un "soldado federal" esmaltado en azul y blanco que circulaba como prendedor ${ }^{35} \mathrm{y}$ asentó su presencia territorial en las Provincias de Buenos Aires, Santa Fe, Santiago del Estero, San Juan, Salta, la entonces Gobernación Militar de Comodoro Rivadavia, Río Negro, Neuquén, Córdoba, Misiones, Chaco y Entre Ríos. ${ }^{36}$ Además, comenzó a sacar una prensa propia llamada Juan Manuel. La misma se publicó en papel de diario y contaba con ocho páginas. Dicho periódico sirvió como canal de difusión de las intervenciones y debates que la Comisión buscaba desarrollar, resaltando la "reivindicación de los valores propios". Esto quedó expuesto en su propia iconografía: un soldado federal que, según explicaron, expresaba la voluntad de empuñar "la lanza montonera con la banderola de Rosas y los caudillos para bregar por nuestra aspiración suprema a una Argentina heroica, digna y soberana". ${ }^{37}$ Pero el movimiento se desenvolvía dentro de "la más absoluta precariedad", lo cual redundó en la rápida interrupción del periódico que llegó a sacar apenas tres números. En el tercero, y último, invitaron a todos los miembros, adherentes y simpatizantes a participar de la suscripción a un empréstito público por parte de la CPAPRJMR, con ánimo de poder desarrollar las tareas planteadas por la misma, seguir desarrollando dicho periódico, así como una editorial encargada de publicar títulos revisionistas. Con tal motivo se creó una Comisión Fiscalizadora de Ingresos e Inversiones, que contaba entre sus miembros, con Manuel Oscar Heredia, Julio Molina, Carlos Hansen, John W. Cooke y Raúl A. Roux. ${ }^{38}$ Si bien la propia prensa publicitó en sus números una lista de precios de la "Editorial Juan Manuel", no tenemos ninguna certeza de que haya llegado a concretarse realmente. De la conformación de esta última comisión queremos destacar la presencia de Cooke y Roux en la CPAPRJMR. El primero se desempeñaba entonces como diputado de la nación y sería un engranaje fundamental en los vínculos entre rosismo y peronismo de allí en más. Ese año había votado en contra de realizar un homenaje al General Justo José de Urquiza en la cámara baja, con motivo de cumplirse cien años de su

\footnotetext{
${ }^{34}$ María Laura Reali y Olga Echeverría han dejado entrever que puede haber existido aquí cierta influencia del nacionalismo uruguayo identificado con la figura de Herrera, con quien Ernesto Palacio y José María Rosa comenzaron a intercambiar correspondencia a partir de la década del cuarenta. A los que debe sumarse Manuel Gálvez, quien mantenía este tipo de intercambios de manera previa. Aquella experiencia, a los ojos de los nacionalistas argentinos, había logrado tener eficacia en conjugar apelaciones al pasado para intervenir políticamente sobre su presente, con capacidad de movilización social (Echeverría y Reali, 2016, p. 68).

${ }^{35}$ Juan Manuel, 1 de noviembre, p. 2.

${ }^{36}$ Juan Manuel, 26 de julio, p. 6; Juan Manuel, 9 de agosto de 1951, p. 6.

${ }^{37}$ Juan Manuel, 26 de julio de 1951, p. 1.

38 Juan Manuel, 26 de julio de 1951, pp. 1-2.
}

Anuario de la Escuela de Historia Virtual - Año 12 - N 19 - 2021: pp. 122-143. ISSN: 1853-7049 
pronunciamiento..$^{39} \mathrm{Y}$, si bien mantuvo desde esta época relaciones con el IIHJMR, fue recién en 1953 que llevó adelante su afiliación. ${ }^{40}$ Por su parte, Roux, quien había nacido en el Uruguay, fue uno de los precursores de la historieta local y desde allí indagó centralmente la historia argentina. Publicó, en un primer momento, en revistas como $E l$ Tony y Caras y Caretas, y más tarde -en las décadas de 1940 y 1950- en Mundo Argentino y Patoruzito. Fue el ilustrador del Boletín La Estrella Federal, símbolo de revisión en la historia. Por la cultura popular histórica que el IIHJMR comenzó a sacar en 1959.

Para fines de noviembre de 1951 estaba convocada una "gran asamblea" de la Secretaría General del movimiento, con ánimo de reunir a todas las Juntas Provinciales y Territoriales, Filiales, Delegaciones e Institutos afines, a realizarse en la ciudad de Buenos Aires. La misma tenía planteada como cuestión central la constitución de un Consejo Consultivo Federal con representantes de todas las provincias y gobernaciones. ${ }^{41}$ No tenemos información certera sobre la concreción de dicha asamblea, así como tampoco hemos podido reconstruir en qué momento y por qué razones esta organización dejó de existir como tal. Lo que sí sabemos es que en el transcurso del año 1954, unos pocos días antes del lanzamiento de la OPRRR, Alejandro Olmos presentó a título personal, y como "particular"- un proyecto de ley en la cámara de diputados de la nación que tenía por fin disponer la repatriación de los restos de Rosas..$^{42}$ El hecho fue relevado -entre otras- por la revista Hechos en el mundo, donde Olmos venía publicando una serie de notas justificatorias de dicha iniciativa, contemplando -en alguna de ellaslos reclamos realizados con anterioridad por la CPAPRJMR.

\section{La estrella federal como emblema}

El 18 de junio de 1954 quedó constituida, en la ciudad de Eva Perón (actualmente La Plata), la OPRRR. Ese día se establecieron sus autoridades, su sede y su emblema: "la Estrella Federal, símbolo de la Unidad Nacional". Por medio de su primer comunicado zanjaron una nueva etapa en la historia de la tradición rosista al trazar 102 años de "lucha por la definitiva liberación", haciendo referencia explícita a la salida de Rosas del país en 1852. Así las cosas, este representaba "el altivo espíritu soberano e independiente del gaucho argentino". ${ }^{43} \mathrm{Si}$ bien la apelación a un nacionalismo telúrico para referirse a su figura no era una novedad, y tampoco lo era su uso arquetípico en la contienda con los "intereses foráneos", sí vale subrayar cierto punto de inflexión en su inscripción tácita en un proceso largo de lucha por la liberación.

\footnotetext{
39 "Una actitud", en: Juan Manuel, N¹, pág. 5.

${ }^{40}$ Ficha de afiliación al IIHJMR, en: AR-BNMM-ARCH-AE-JWC, Caja 1/ Carpeta 1 (acreditaciones).

${ }^{41}$ Juan Manuel, 1 de noviembre de 1951, p. 8.

${ }^{42}$ Dirección de archivo, publicaciones y museo de la cámara de diputados de la nación/Expedientes, Caja $\mathrm{N}^{\circ}$

2, 139-p-1954.

${ }^{43}$ BIIHJMR, año VII, N 19-20, mayo-julio de 1954, p. 3.
} 
Si la comisión de 1934 había tenido por tarea central, bregar por el "justo reconocimiento" de Rosas en la nómina de héroes de la patria; y la comisión de 19491951 había movilizado el sentido de Rosas como símbolo de la "unidad espiritual" entre los argentinos; el problema de la "liberación" suponía algo distinto. ${ }^{44}$ Vale subrayar que, si bien esta consigna estaba presente en el imaginario nacionalista previo al peronismo, todo indica que su poder de fuego creció en esos años de la mano de la apropiación y uso que ese proceso político le otorgó. Esto, junto con otros elementos que iremos refiriendo más adelante, nos lleva a pensar que la OPRRR habría compartido una arena común con el imaginario peronista mayor que su experiencia inmediatamente anterior. ${ }^{45}$ Un punto de continuidad importante entre ambas experiencias puede rastrearse en la lógica organizativa, ya que la OPRRR desarrolló un importante anclaje de base territorial -mucho mayor que la anterior-46 en distintos rincones del país y con asiento en distintos sectores de la sociedad. Más aún, no hay que perder de vista que, a excepción de Alejandro Olmos, todos los miembros de la Junta Ejecutiva Central de la CPAPRJMR formaron parte activa de la OPRRR. ${ }^{47}$

Desde las páginas del Boletín del Instituto de Investigaciones Históricas Juan Manuel de Rosas (de aquí en más BIIHJMR) el Instituto dejó explícita la posición que asumió en esta nueva contienda por la repatriación de los restos de Rosas. Expusieron también las diferencias y continuidades con experiencias anteriores, sosteniendo que "la iniciativa no era nueva", ya que "en épocas anteriores -hace de esto fácilmente veinte años- hubo quienes se preocuparon por impulsar una idea de suyo noble e inspirada en el más vehemente deseo de justicia histórica". Agregaban que su actitud de mantenerse "siempre un tanto al margen" se debió al hecho de que antes que la "repatriación material de los restos interesaba lo que se llamó la repatriación de la conciencia argentina" y en ese sentido Rosas era su "exponente más cabal". Así, el Instituto había entendido que era tarea primordial trabajar para "contribuir a la difusión de la verdad histórica, destruir la falsificada versión de los vencedores y consolidar definitivamente el relato de los hechos del pasado sobre la base de un revisionismo científico, imparcial, honrado en la exposición y en la interpretación tanto de hombres cuanto de procesos". En ese sentido, para 1954 "las cosas eran muy diferentes", ya que una "nueva generación y algunos hombres de las anteriores” habían fundado el IIHJMR en 1938, y desde allí

\footnotetext{
${ }^{44} \mathrm{Si}$ bien es posible rastrear el uso de esta consigna en algún escrito de aquellas figuras que circularon por el IIHJMR desde su formación, como es el caso de un texto de Ramón Doll de 1939; no podemos decir lo mismo de la RIIHJMR donde dicho concepto no tituló ninguno de los artículos publicados durante su primera época. Un antecedente importante en este sentido fue la ALN, desde la tradición nacionalista.

${ }^{45}$ Decir esto, no implica para nada pensar en un vínculo lineal entre rosismo y peronismo. Coincidimos con lo afirmado por Julio Stortini respecto a la "actitud expectante" que el IIHJMR tomó para con el fenómeno peronista en aquellos años, y creemos que es posible pensar en esta clave la relación de otros sectores rosistas, para con la experiencia de gobierno en curso (Stortini, 2004, p. 249).

${ }^{46}$ En el informe de la DIPPBA, esta experiencia organizativa fue destacada como la mayor previa a la Comisión presidida por Anchorena de fines de los años sesentas y los primeros setentas, y se subrayó el uso de la estrella federal como emblema. Archivo CPM/ Fondo DIPPBA, Mesa Referencia 15456, p. 57.

${ }^{47}$ Desconocemos las razones por las cuales Alejandro Olmos no formó parte de la OPRRR.
} 
dieron "impulso definitivo a la tarea reivindicadora". Los años que le siguieron "se caracterizan por una intensa campaña de penetración popular de la verdad histórica" que estaban dando sus frutos tras diecisiete años ${ }^{48}$.

El diario La Época, que participó activamente de la campaña pro-repatriación, afirmó que la "satisfacción con que fue recibido en todo el país el propósito de la 'Organización Popular por la Repatriación de los Restos de Rosas' revela que interpreta un anhelo nacional largamente acariciado". ${ }^{99}$ Así, fortines gauchos, peñas folklóricas, entidades culturales y deportivas de todo el país se sumaron a la iniciativa. ${ }^{50}$ El 29 de junio quedó constituido el núcleo directivo de la misma. Cabe subrayar que, si bien buena parte de las autoridades eran miembros del IIHJMR, dicha iniciativa buscó contener, y todo indica que así lo hizo, a otros sectores de la vida política, artística y deportiva de la sociedad argentina de entonces. Así, una diversidad de figuras como el dramaturgo Alberto Vacarezza, la actriz Lola Membrives, el investigador del folklore Juan Alfonso Carrizo, el sindicalista Rolando Hnatiuk, el futbolista Juan Manuel García Pérez o el dibujante Raúl Roux, asumieron responsabilidades dentro de esta Organización, o bien apoyaron explícitamente la iniciativa. A esto se sumó la propagación de comisiones locales por todo el país, así como la adhesión de grupos de estudiantes, ${ }^{51}$ artistas, $^{52}$ asociaciones de "gente de color" ${ }^{53}$ o sindicatos. ${ }^{54}$

Para mediados de julio, ya se afirmaba que en "las diez y seis provincias y en los territorios nacionales diversos núcleos de opinión están realizando los preparativos para dejar constituidas las respectivas filiales que tendrán como jurisdicción el ámbito provincial". ${ }^{55}$ En ese sentido, "en vista de la gran cantidad de núcleos vecinales que en la Capital Federal y en el interior, han expresado trabajar y colaborar en la campaña", desde la Comisión Organizadora Provisoria de la OPRRR, se plantearon una serie de criterios. Este importante proceso organizativo es una clave fundamental para pensar la rápida difusión que el símbolo de la estrella federal pudo haber tenido en ese contexto a lo largo y ancho del país. ${ }^{56}$ En este sentido desde las páginas de Repatriación, afirmaron:

\footnotetext{
${ }^{48}$ BIIHJMR, mayo-julio de 1954, pp. 1 y 9.

${ }^{49}$ La Época, 21 de junio de 1954, p. 3.

${ }^{50}$ La Época, 22 de junio de 1954, p. 2.

${ }^{51}$ Cabe destacarse el rol en la campaña de la Unión de Estudiantes Secundarios (UES) creada en 1953 por el entonces Ministro de Educación de la Nación, Armando Méndez San Martín.

${ }^{52}$ Lola Membrives, Leonor Rinaldi y Enrique Serrano, en: La Época, 23 de julio de 1954, p. 3.

${ }^{53}$ Crítica, 23 de julio de 1954, p. 5.

${ }_{54}$ Para el caso de los trabajadores ferroviarios, ver: La Época, 2 de julio de 1954, p. 3.

${ }^{55}$ La Época, 14 de julio de 1954, p. 5.

${ }^{56}$ Eduardo Rosa, quien fue miembro de la OPRRR, afirmó haber visto este símbolo por primera vez en el marco de dicha organización. Entrevista propia, 23 de noviembre de 2017. Agradezco especialmente su testimonio por haberme brindado las primeras claves que me permitieron identificar este punto de inflexión fundamental en la historia del símbolo. En el mismo sentido, Ramón Torres Molina recordó haber retirado -también ese año- en la sede central de la organización, en la ciudad de La Plata, su primer "distintivo con forma de estrella federal”. Comunicación personal por correo electrónico, 11 de abril de 2020.
} 
Millares de distintivos se han distribuido en todo el país. La Estrella Federal gana al pueblo. En el local de la calle Florida 334 de la Capital Federal y en los locales de las distintas filiales y en la Sede Central de la Organización Popular en la calle $7 n^{\circ} 1082$ de la ciudad Eva Perón, Prov. de Bs. Aires, es incesante el desfile de personas que vienen a comprar distintivos y a firmar el Petitorio.

La simpática Estrella Federal, símbolo lleno de tradición y de contenido telúrico, adorna millares de ojales argentinos; invitamos a quienes aún no la tengan a que se apresuren a conseguirla para lucirla en la solapa.

La Estrella Federal unirá así a los argentinos de todos los sectores, solidarizándolos en el amor y en la justicia por las cosas patrias. ${ }^{57}$

A finales de julio, se desarrolló una nueva reunión del Consejo Plenario Nacional de la OPRRR. El acto "congregó a un público que colmaba la capacidad de la sala y entre el cual se advirtió la presencia de destacados escritores, periodistas, dirigentes gremiales y delegados de centros folklóricos de la provincia de Buenos Aires, la Capital Federal y el interior del país". El mismo inició con la ejecución del himno nacional, luego de lo cual tomó la palabra el secretario de la Junta Ejecutiva Dr. Juan Antonio Trevisan. Le siguió el presidente de la OPRRR, José María Rosa, quien destacó las "innumerables adhesiones recibidas" para que los restos de Rosas "por fin, reposen en la pampa que tanto amó". Terminó su discurso declarando en ejercicio de sus funciones a los miembros del Consejo Plenario Nacional, a quienes impuso en la solapa la insignia de la OPRRR: una estrella federal. En ese sentido recordó que “dicho emblema había sido instituido por la entidad en recuerdo de que tal insignia le fue acordada al general Rosas por la Legislatura de Buenos Aires en carácter de condecoración por la conquista del desierto". Aquí yace un elemento fundamental de la historia de este símbolo, ya que quedan planteados cuáles fueron los materiales con los que el mismo se confeccionó originariamente. La ley que reglamentó otorgar dicha conmemoración a Rosas en 1834 expresaba que la "medalla será de oro en forma de sol, con círculo de brillantes, y su colocación pendiente del cuello".58 Si la morfología del nuevo emblema aludía a aquella, la manera de denominarla era nueva. La misma apeló a un sintagma o concretamente al nombre de una planta, que venía circulando entre distintos modos de representar la época de Rosas, desde décadas anteriores. Así quedaba plasmada la operación de inventiva del símbolo en cuestión. Ese mismo día anunciaron para la siguiente semana la circulación del "petitorio del pueblo argentino" para solicitar a las autoridades la repatriación de los restos de Rosas para ser firmados "por todos los argentinos que lo deseen" en las filiales de la OPRRR. ${ }^{59} \mathrm{Y}$ en el mes de septiembre comenzaron a publicar una prensa propia: Repatriación.

\footnotetext{
${ }^{57}$ Repatriación, 22 de septiembre de 1954, p. 5.

${ }^{58}$ Rasgos de la Vida Pública de S. E. El Sr. Brigadier General D. Juan Manuel de Rosas: Trasmitidos a la Posteridad por decreto de la H. Sala de R.R. de la Provincia, 1842, p. 38.

${ }^{59}$ Crítica, 31 de julio de 1954, p. 3.
}

Anuario de la Escuela de Historia Virtual - Año 12 - N 19 - 2021: pp. 122-143. ISSN: 1853-7049 
La campaña finalmente se lanzó, tiempo después, con un acto que colmó la capacidad del Teatro Augusteo de la ciudad de Buenos Aires. Se hicieron presentes "destacadas personalidades de todos los sectores y actividades nacionales, desde nutridas delegaciones de representaciones gremiales hasta grupos del interior que llevaban al acto la representación de las filiales de sus respectivas provincias; asistieron miembros de número y autoridades de diversos Institutos y Academias especializadas de historia". El acto contó con los discursos de Cesar Aranguren, John W. Cooke, Enrique M. Mayochi, José María Rosa y Alberto Vaccarezza. Tras finalizar "se vio que algunas personas, agitando símbolos de la repatriación, tales como retratos de Rosas y estrellas federales cortada en paño [sic] incitaban al público a dirigirse en manifestación hacia el centro". Esta descripción nos permite pensar que los usos de la estrella federal no se restringieron necesariamente a los prendedores que adornaban los ojales de los sacos, sino que pudieron haber circulado -ya entonces- en otros soportes. Una "verdadera multitud" se movilizó hasta llegar a Florida al 334, donde se encontraba la filial Capital Federal de la OPRRR. Allí, desde el balcón, uno de los miembros del plenario afirmó "ahora pueden venir los restos de Rosas, porque la Patria ha conquistado aquellos bienes por los cuales él tanto luchó". ${ }^{60}$

El devenir de esta experiencia, se pierde para los meses siguientes. Si bien no tenemos indicios certeros para afirmarlo, encontramos sumamente probable que el conflicto desencadenado entre el gobierno peronista y la Iglesia durante los últimos meses de 1954, con el impacto que esto generó sobre todo en los sectores nacionalistas católicos y teniendo en cuenta la representatividad que estos tenían dentro de la iniciativa repatriadora, haya hecho insostenible la convivencia de muchos de los sectores que formaban parte de la OPRRR.

\section{A modo de cierre}

El análisis pormenorizado del proceso histórico recorrido en estas páginas, nos ha permitido adentrarnos en el complejo devenir de la tradición rosista a lo largo de la primera mitad del siglo XX. Si algo podemos decir, llegado a este punto, es que el rosismo no ha sido una cosa igual a sí misma, así como tampoco es posible reducir su historia a lo hecho por el IIHJMR, ni a los discursos historiográficos del revisionismo. Más aún, centrarnos en las experiencias organizativas que reclamaron la repatriación de los restos de Rosas, nos ha permitido no solo ver las distintas maneras en que estos colectivos usaron su figura para apelar a lo nacional a lo largo de veinte años. Sino que al mismo tiempo nos ha abierto la posibilidad de expandir el horizonte de aquello que, entendemos, debe ser comprendido a la hora de identificar y reconstruir la historia del rosismo durante el siglo XX. Es decir que nos ha permitido aproximarnos a distintas formas de actualización de su identidad en distintas coyunturas, con distintas

\footnotetext{
${ }^{60}$ Repatriación, 22 de septiembre de 1954, p. 3.
} 
intencionalidades y a las cuales no habríamos llegado si nuestra mirada se restringía a un registro estrictamente historiográfico. De esa manera, por ejemplo, habríamos perdido de vista las trayectorias rosistas de figuras no menores de la coyuntura post-55 como Cooke y Olmos.

Más aún, haciendo uso de la metáfora levistraussiana, bien vale decir que el Rosas construido en el propio devenir de la experiencia rosista de esos años es más homologable al bricoleur, que se hace a sí mismo, de manera contingente, utilizando residuos y restos de acontecimientos que se elaboran y reelaboran, que a una entelequia inamovible capaz de movilizar un significado único a través del tiempo (Levi Strauss, 1984, p. 42). Decir esto no implica desconocer estabilidades. El rosismo habitó dentro de un universo particular -el nacionalismo de esos años-, y fue capaz de movilizar una serie de elementos ordenadores que, a nuestro entender, le dieron cariz propio. Nos referimos a la identificación de Rosas como la raíz telúrica de la nación; cierta aversión a la injerencia extranjera, una peculiar forma de vinculación entre el líder y su pueblo y, sobre todo, la idea de que la explicación de otra nación posible no se apoyaba en elementos abstractos sino en una vía que el país había efectivamente transitado sin llegar a consolidarse como tal, por una interrupción. Rosas era una usina a donde ir a buscar el pasado, el presente y el futuro. Pero la manera en la cual se amalgamaron estos sentidos y sus contenidos estuvo dada por el cuadrante ideológico que ocupara el utilitario en cuestión y la coyuntura en la cual estuviera inserto. Sobre esos cimientos se articularon una cantidad enorme de otros sentidos -incluso contradictorios- en torno a su figura. Pero todo esto fue fruto también del sentido histórico sedimentado en la propia experiencia de esos años. Las casi ocho décadas que separaron la muerte de Rosas de la constitución de la OPRRR en 1954 dan cuenta de dos elementos fundamentales. En primer lugar, el pasaje de una posición subalternizada en el campo de fuerzas de los imaginarios sociales de la nación, a una posición emergente; y, en segundo lugar, la construcción -como fruto de ese mismo proceso-de una tradición política con identidad propia, munida de sus rituales, sus símbolos y sus lugares. Así las cosas, la experiencia de mayor envergadura de estas puso en escena al símbolo de la estrella federal en un contexto particular. Su emergencia, impacto, circulación y potencia no pueden desanclarse del contexto en el que -ya como estrella roja de ocho puntas- se convirtió en un símbolo de identificación colectivo. ¿Acaso es posible pensar en la rápida circulación que dicho símbolo tuvo, desanclado de la enorme red organizativa que el rosismo venía construyendo a lo largo y ancho del país hacía tiempo? ¿Es posible pensar la construcción y devenir de ese emblema sin tener en cuenta el modo en que la iniciativa que le dio origen articuló a un conjunto heterogéneo de sectores bajo una forma concreta de apelar a la nación? ¿Es posible, teniendo en cuenta la diversidad que la OPRRR contuvo, desconocer las formas de circulación previa de dicho motivo (sea como planta o simplemente como sintagma) de cara a su nueva síntesis? ¿Es posible separar el destino de la estrella federal o, al menos, su primer desplazamiento inmediato a su incluisión en la constelación de símbolos de la resistencia peronista, sin tener en cuenta el contexto de 
su invención en los epílogos del peronismo? Más aún, ¿Es posible pensar que pudo haber sido ese lugar liminal, adentro y afuera del peronismo, el que le dio un dinamismo propio cuando todas las formas de apelar a dicha identidad quedaron prohibidas?

El peronismo sin duda eclipsó la historia argentina. Pero el rosismo ya estaba allí cuando el peronismo se estaba confeccionando a sí mismo. Más aún, sin duda que el rosismo mismo se vio absolutamente sacudido por el advenimiento de ese proceso político. Pero sin duda también se vio fuertemente seducido por la posibilidad histórica de incrustar sus representaciones en la constelación de una nación, que se estaba pensando nuevamente a sí misma. De la mano del devenir de los acontecimientos, el peronismo en ciernes y el rosismo consolidado entablarán de ahí en más una tensión creativa en la que la armonización, o no, de sus piezas ira al compás de los ritmos de la historia. En ese contrapunto, algo nuevo estaba sucediendo en la historia de la estrella federal.

\section{Referencias bibliográficas}

Barletta, A. M. y de Amézola, G. (1992). Repatriación: Modelo para armar. Tres fechas en la repatriación de los restos de Juan Manuel de Rosas (1934-1974-1989). En Mitos, altares y fantasmas: Aspectos ideológicos en la historia del nacionalismo argentino (pp. 8-61). La Plata: UNLP. FAHCE. Disponible en: http://www.memoria.fahce.unlp.edu.ar/libros/pm.67/pm.67.pdf (Fecha de descarga 3/10/2018).

Besoky, J. L. (2016). La derecha peronista. Prácticas políticas y representaciones (1943-1976) (Tesis de Doctorado en Ciencias Sociales). Universidad Nacional de La Plata, La Plata.

Cattaruzza, A. (2007). Los usos del pasado. La historia y la política argentinas en discusión, 1910-1945. Buenos Aires: Sudamericana.

Cattaruzza, A. (2017). El pasado como problema político. Anuario IEHS, 32 (2), 59-78.

Cobos Daract, J. (1921). Estrella Federal. Buenos Aires: Editorial TOR.

Coudannes Aguirre, M. (2009) ¿Profesionales o políticos de la historia? La historiografía santafesina entre 1935 y 1955. En T. Suárez y S. Tedeschi (Comps.), Historiografía y sociedad: discursos, instituciones, identidades (pp. 27-68). Santa Fe: Centro de Publicaciones de la Universidad Nacional del Litoral.

Descalzo, B. (1949). Contribución al esclarecimiento de episodios relacionados con la vida y actos del libertador y del gobernador general Juan Manuel de Rosas. Buenos Aires: Instituto Nacional Sanmartiniano.

Devoto, F. y Pagano, N. (2009). Historia de la historiografía argentina. Buenos Aires: Sudestada.

Echeverría, O. y Reali, M. L. (2016). Encuentros y disidencias políticas, ideológicas e historiográficas en los revisionismos rioplatenses (décadas de 1930 y 1940). En J. F. Bertonha y E. Bohoslavsky (Comps.), Circule por la derecha. Percepciones, redes y contactos entre las derechas sudamericanas, 1917-1973 (pp. 65-91). Buenos Aires: UNGS. 
143 | Las experiencias organizativas por la repatriación de los restos de Rosas

Fernández Lalanne, P. E. (1989). Los Uriburu. Buenos Aires: Emecé.

Galasso, N. (2006). La vida de un militante. En A. Olmos, Todo lo que usted quiso saber sobre la deuda externa y siempre se lo ocultaron: quiénes y cómo la contrajeron (pp. 19-32). Buenos Aires: Peña Lillo-Continente.

Goebel, M. (2013). La argentina partida. Nacionalismos y políticas de la historia. Buenos Aires: Prometeo.

Halperín Donghi, T. (2003). Argentina y la tormenta del mundo. Buenos Aires: Siglo XXI.

Hobsbawm, E. (2002). Introducción: La invención de la tradición. En E. Hobsbawm y T. Ranger (Coords.), La invención de la tradición (pp. 7-21). Barcelona: Crítica.

Levi Strauss, Cl. (1984). El pensamiento salvaje. México: Fondo de Cultura Económica.

Luna, F. (1998). La nueva estrella federal. En F. Luna, La Santa Federación. Momentos claves de la historia integral de la Argentina, Vol. 3 (pp. 9-28). Buenos Aires: Planeta.

Macor, D. (1995). Imágenes de los años treinta. La invención de la década del treinta en el debate político intelectual de la Argentina sesentista. Santa Fe: UNL.

Olmos, A. (1949). Sepa el pueblo la verdad, Buenos Aires: sin datos editoriales.

Pankonin, L. N. (2019). Los avatares del rosismo y la historia de los usos de la estrella federal (1921-1954) (Tesis de maestría). Universidad Nacional de San Martín, Buenos Aires.

Quattrocchi Woisson, D. (1995). Los males de la memoria. Historia y política en la Argentina. Buenos Aires: Emecé.

Reali, M. L. (2016). Al margen de "El Relato". Circulación transnacional de lecturas revisionistas sobre el pasado en América Latina (1900-1930), Nuevo Mundo Mundos Nuevos [En ligne], URL: http://nuevomundo.revues.org/69313. (Fecha de descarga 27/7/2020).

Reali, M. L. (2015). Herrera. La revolución del orden. Discursos y prácticas políticas (18971929). Montevideo: EBO.

Rosa, J. M. (1979). Historia argentina, t. 12. Buenos Aires: Editorial Oriente.

Rosa Lojo, M. (1998). La princesa federal. Buenos Aires: Editorial Planeta.

Rosa Lojo, M. (2005). Finisterre. Buenos Aires: Editorial Sudamericana.

Stortini, J. (2004). Historia y política. Producción y propaganda revisionista durante el primer peronismo. Prohistoria: historia, políticas de la historia, 8, 229-250.

Thompson, E. P. (2012). La formación de la clase obrera en Inglaterra. Madrid: Capitán Swing.

Williams, R. (2009). Marxismo y Literatura. Buenos Aires: Las cuarenta.

Para citar este artículo:

Pankonin, Leandro Nicolás (2021). Las experiencias organizativas por la repatriación de los restos de Rosas y los orígenes de la estrella federal como símbolo de identificación colectiva (1934-1954). Anuario de la Escuela de Historia Virtual, 19, 122-143. 